\title{
What Can Appalachian Pediatric Networks Do to Improve Disaster Pre- paredness and Health Outcomes? Examining Characteristics of Pediatric Networks in the United States to Identify Differences between Appalachian and Non-Appalachian Collaborations
}

\author{
Lauren Wallace, DrPH ${ }^{1 *}$, Andrew C. Rucks, PhD ${ }^{2}$, Peter M. Ginter, PhD ${ }^{3}$, Rongbing Xie, DrPH ${ }^{4}$, Charles R. Katholi, \\ PhD ${ }^{5}$, Faustina Bello-Ogunu, MSN, $\mathbf{R N}^{6}$ \\ ${ }^{1,6}$ Department of Public Health Sciences, College of Health and Human Services, University of North Carolina at Charlotte, United States. \\ ${ }^{2,3}$ Department of Health Care Organization and Policy/University of Alabama at Birmingham, United States. \\ ${ }^{4}$ Department of Surgery/University of Alabama at Birmingham, United States. \\ ${ }^{5}$ Department of Biostatistics/University of Alabama at Birmingham, United States.
}

\begin{abstract}
Article Details
Article Type: Review Article

Received date: $25^{\text {th }}$ November, 2019

Accepted date: $26^{\text {th }}$ December, 2019

Published date: $30^{\text {th }}$ December, 2019

"Corresponding Author: Lauren Wallace, Department of Public Health Sciences, College of Health and Human Services, University of North Carolina at Charlotte, 9201 University City Boulevard CHHS 427D, Charlotte, NC 28223; United States. E-mail: lauren.wallace@uncc.edu

Citation: Wallace L (2019) What Can Appalachian Pediatric Networks Do to Improve Disaster Preparedness and Health Outcomes? Examining Characteristics of Pediatric Networks in the United States to Identify Differences between Appalachian and Non-Appalachian Collaborations. J Pub Health Issue Pract 3: 154. doi: https://doi.org/10.33790/jphip1100154. Copyright: (C2019, This is an open-access article distributed under the terms of the Creative Commons Attribution License 4.0, which permits unrestricted use, distribution, and reproduction in any medium, provided the original author and source are credited.
\end{abstract}

\begin{abstract}
Introduction: Living in the Appalachian Region of the United States (US) has been linked with poorer pediatric health outcomes, particularly for children in low income families living in rural areas.

Purpose: We endeavored to describe the characteristics of the Appalachian and non- Appalachian pediatric emergency networks in the US and to determine if pediatric healthcare networks in the Appalachia differ from networks elsewhere in the U.S. according to size, whether they were inter- or intra-state, and intensity of collaboration.
\end{abstract}

Methods: Data were collected using a two-stage survey process. The first survey was used to identify networks. The second survey assessed disaster preparedness capabilities and achievements of each identified network, degree of fund sharing, and the intensity and formality of information sharing among network partners. Networks were separated into Appalachia or non-Appalachia networks based on state location.

Results: Appalachian networks were more likely to be interstate and operating at the highest stage of network development compared to non-Appalachian networks, but were less likely to share funding among network partners.

Conclusion: Despite consistently insufficient pediatric capacity and repeated calls for collaboration among pediatric care providers, only three out of seventeen identified pediatric networks were operating in Appalachia. Operating in Appalachia was associated with less fund sharing, although Appalachian networks were more likely to have achieved the highest stage of network development. Developing new pediatric networks and increasing the intensity of collaboration (i.e., increased levels of fund sharing) among existing networks may improve disaster preparedness, network operations, collaboration, and health outcomes in Appalachian states.

Keywords: Disaster preparedness, Rural disparities, Pediatric networks, Appalachian

\section{Introduction}

The Appalachian region of the United States, made up of 420 counties

J Pub Health Issue Pract

Volume 3. 2019. 154 in thirteen states spanning from southern New York to northern Mississippi, is home to an estimated 25 million people [1]. Living in Appalachia has been linked with poorer pediatric health outcomes, particularly for children in low income families living in rural areas. Problems accessing appropriate pediatric care is a nationwide problem; across the country, most children who sought care in emergency departments $(69.0 \%)$ received care in Emergency Departments (EDs) averaging fewer than 15 pediatric patients per day [2]. For Appalachian families, limited access due to insufficient pediatric capacity is compounded by access factors including increased travel distances to obtain care, poverty, and lack of insurance [3].

Problems related to access and capacity limitations of pediatric healthcare organizations are compounded during disasters. The Institute of Medicine (IOM) reported that only six percent of the emergency departments in the US have all the necessary supplies, facilities, or personnel to deal with pediatric emergencies [4]. In addition, the American Academy of Pediatrics (AAP) Committee on Pediatric Emergency Medicine identified pediatric ED overcrowding as a significant constraint to providing adequate pediatric emergency care in general and a significant constraint during disaster response [5-7].

Developing networks of healthcare organizations can increase surge (as in a temporary increased demand for services) and nonsurge pediatric capacity. Collaborative networks would benefit rural Appalachian communities and would allow them be better equipped for the increasing frequency and intensity of hazardous events.

\section{Background}

The short-supply of resources and children's hospitals routinely operating at or near capacity combine to produce little available reserves for even a modest surge of inpatients [8,9]. In addition to their critical role during disasters, networks of pediatric care providers are urgently important to the health and wellbeing of communities before and after disasters occur.

Several agencies and organizations have devoted research or other efforts and resources to the topic of disaster-related regional JPHIP, an open access journal ISSN- 2581-7264 
and networks. For example, in its 2010 report to the President, the National Commission on Children and Disasters (NCDD) recommended that "resources for a formal regionalized pediatric system of care to support surge capacity during and after a disaster" should be provided [10]. This recommendation was made earlier by the IOM in 2006 [4] and independently corroborated by a peerreviewed paper published in the same year [11]. Further, the AAP, the Office of the Assistant Secretary for Preparedness and Response (ASPR) Hospital Preparedness Program (HPP), and the IOM have focused webinars and workshop presentations on the topic of regional collaborations and networks. There is significant evidence of the need for the formation of regional collaborations and networks of providers for pediatric surge. As Krug and colleagues note "enhanced partnerships between pediatricians and state or local health department representatives would likely result in improved pediatric preparedness planning" [12].

Despite the evidence of need, formal regional networks have been slow to develop perhaps because they are difficult to organize, develop, and manage, and there may be numerous legal, infrastructural, and operations barriers to their formation and maintenance [13]. Even with the inherent difficulties, there are a number of nascent and informal networks in various stages of development and fewer formally established regional pediatric surge networks; however, beyond networks for routine care, such as trauma, perinatal, and referral collaborations, little is known concerning the development, characteristics and effectiveness of these networks. Therefore, conducting an inventory and analysis of US networks and other collaborative efforts to address pediatric surge capacity is an important step towards achieving pediatric preparedness. Further, such an inventory will provide guidance for improving existing networks and support the creation of new networks.

\section{Network Rationale}

Forming coalitions among organizations has become an expectation of public health agencies at the local, state, and national levels [14]. Indeed, partnering and community involvement are essential in the Public Health Accreditation Board (PHAB) process for state, local and tribal public health accreditation [15]. "Mobilizing community partnerships" is one of the essential public health services defined by the IOM [16], and the National Public Health Performance Standards includes the use of partnership strategies as a performance measure [17].

With the passage of the Pandemic and All-Hazards Preparedness Act (PAHPA, Public Law No. 109-417) in 2006, the Congress authorized the HPP. The program is managed by the ASPR in the U.S. Department of Health and Human Services. The HPP has placed considerable emphasis on the formation of health care coalitions through its funding efforts. Rambhia and colleagues [18] reported that more than $90.0 \%$ of hospitals participating in the survey were involved in a coalition or network as a result of HPP funding. It is noteworthy that the HPP program applies to all hospitals and is not specific to pediatric specialty hospital or pediatric-focused networks. Toner and colleagues [19] concluded that although the HPP program has contributed to major advancements in individual hospital preparedness and the furtherance of health care coalitions, health care coalitions remain in the early stages of development and are insufficient to effectively respond to widespread catastrophic events.

\section{Network Theory and Research}

Research on factors that promote inter-organizational collaboration is extensive [20-23]. Inter-organizational collaboration in its most advanced stage results in networks - nonhierarchical collections of legally separate organizations interacting for exchange, concerted action, and joint production [24,25]. Networks are sets of collaborative relationships [26], between a lead collaborator and member collaborators [26-30]. Multiple organizations participating in interorganizational relationships established by each lead collaborator

J Pub Health Issue Pract

Volume 3. 2019. 154 has been labeled an "organizational set" by Evan [28] and affirmed by Whetten [31].

Density and Intensity: Two structural properties of interorganizational collaboration have been defined as density and intensity [24, 31,32]. Density is the proportion of all possible linkages within an organizational set [32]. Intensity is the frequency of interaction within an interorganizational set [32]. Essentially, density and intensity of collaboration, are measures of the richness of the collaboration efforts.

Network Development Stage: Networks typically evolve through three Stages: Stage 1 - exchange networks, the sharing of information among participants; Stage 2 - action networks, mutual goal setting and collective action; and Stage 3 - formal networks, long-term formal linkages with memoranda of understanding, memoranda of agreement, and contracts [24, 31-33]. The Stage of network development generally reflects the mutual interdependence within the organizational set and the maturity of the collaborative efforts.

\section{Purpose}

Given the need for the well-functioning networks of pediatric providers before, during, and after disasters, and the unique vulnerability of the Appalachia region, the goal of the study was to describe collaboration among the pediatric healthcare networks in the Appalachia region compared to such networks outside the region. This study investigated pediatric healthcare networks in the Appalachia region to determine if they differ from networks elsewhere in the US in terms of locus (inter- or intra-state), density (measured by number of network members), intensity (measured by collaborative goal achievement), fund sharing, and stage of network development.

\section{Methods}

Data were collected using a two-stage survey process. The first survey (Survey I) was distributed by the AAP disaster preparedness initiatives staff to AAP members and public health representatives in the field and identified networks or groups of collaborators (response rate of $53.0 \%$ with 111 complete responses from 209 attempted or partial completions; $69.0 \%$ of respondents were involved in at least one network). The second survey (Survey II) was sent to the eightytwo Survey I respondents who had identified at least one collaborative network, were based in the U.S., and had agreed to participate in Survey II. Survey II asked about network size, achievement of disaster preparedness goals, frequency and formality of information sharing, and fund sharing among network members (response rate of $62.0 \%$ with 51 responses). Consistent with our study goal, we analyzed with descriptive statistics, i.e. mean. Due to the small sample size, we did not use tests for statistical differences.

Density was measured by the number of partnerships a network possessed; with fewer than 4 partnerships categorized as low density, 4-10 partnerships as medium, and 11 or more as high density (average was 7). Intensity measured the extent to which identified networks achieved each of 15 preparedness goals using a four-point scale, with 1 meaning "does not yet address" and 4 meaning "addresses to a significant extent." Each network could achieve a score in the range of 15 (a score of 1 on each item) to 60 (a score of 4 on each item). Networks classified as "low" if they scored less than 32, "medium" if they scored between 33-47, and "high" if scored higher than 47. The median score was 41 .

Networks were also evaluated based on their stage of development (ranging from 1 to 3 ) as outlined in previous research [24]. The first stage is the sharing of information - i.e. sharing of disaster surge protocols. The second stage is mutual goal setting and collective action - i.e. networks agree upon and word toward mutual goals for each hospital in the network. The third and final stage is the creation of a formal network via long term linkages - i.e. creation and agreement of formal contractual agreements. Information sharing was measured 
using a fivepoint scale with 1 "not at all" and 5 meaning "to a great extent."; degree of formality was assessed with a yes or no question regarding network members had formal agreements or contracts in place. Networks were considered to be in stage 1 if they scored 3 or less for information sharing, stage 2 if scored greater than 3 for information sharing but did not have formal agreements or contracts in place, and stage 3 if they scored greater than three for information sharing and had formal agreements or contracts in place.

\section{Results}

Networks were separated into Appalachian or non-Appalachian networks based on state location. The Kentucky Coalition, Southeastern Regional Pediatric Disaster Surge Network, and the Ohio Coalition were considered Appalachian networks and the remaining networks were considered non-Appalachian. Figure 1 below is a map showing the location of each identified network.

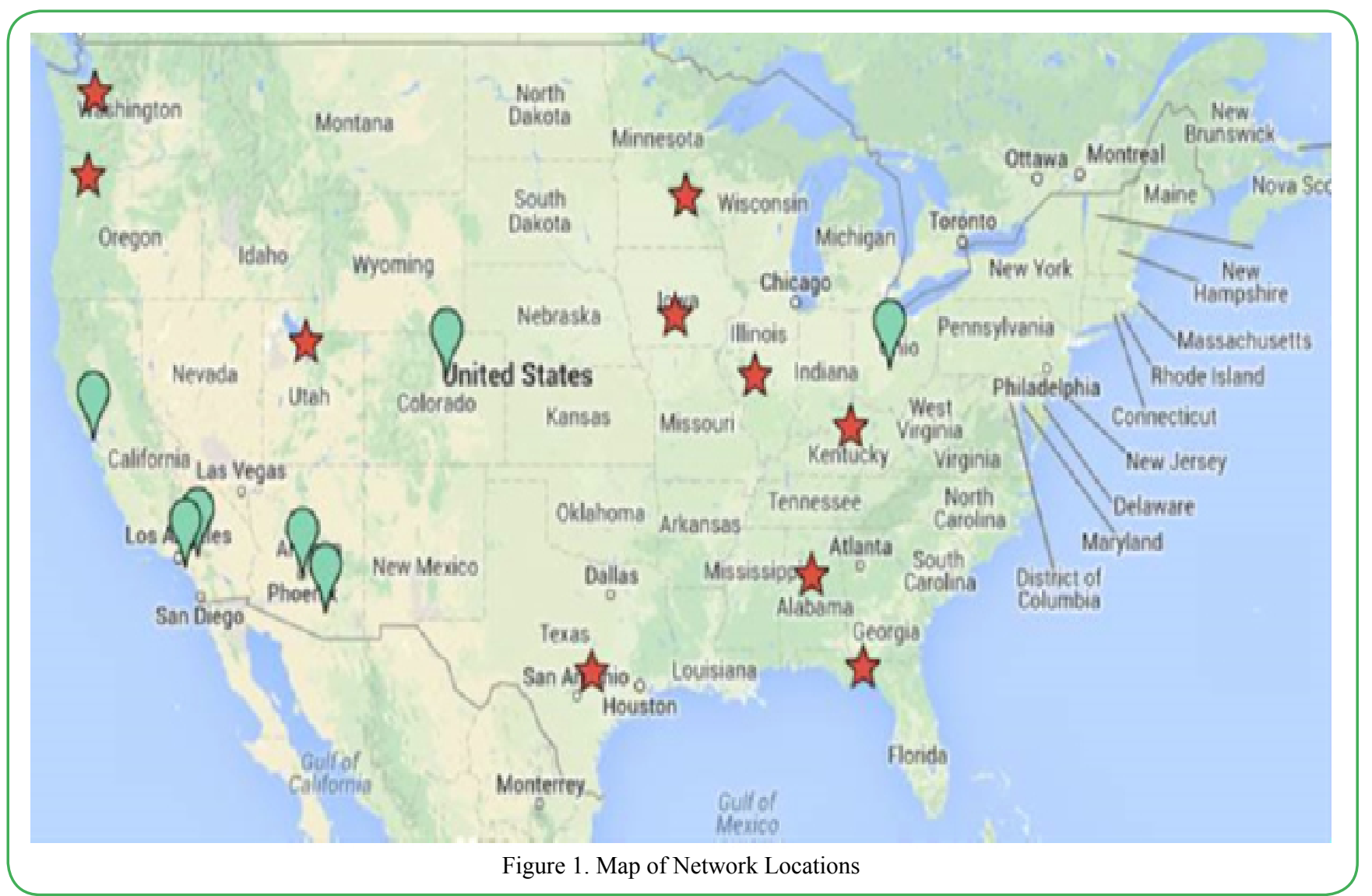

Among interstate networks, five $(50.0 \%)$ were in stage three of network development, three $(30.0 \%)$ were in stage two; one was in for one interstate network). Among intrastate networks, two (29.0\%) stage $1(10.0 \%)$ (stage of network development data was missing were in stage 3 and five $(71.0 \%)$ were in stage 2. Each network's stage of development, density, and intensity scores are presented in Table 1.

\begin{tabular}{|c|c|c|c|}
\hline Coalition Label & $\begin{array}{l}\text { Stage of Network } \\
\text { Development }\end{array}$ & Density of Collaboration & Intensity of Collaboration \\
\hline \multicolumn{4}{|c|}{ Interstate Networks } \\
\hline $\begin{array}{l}\text { Florida Children's } \\
\text { Preparedness } \\
\text { Coalition }\end{array}$ & 2 & High & Medium \\
\hline Illinois Coalition & 3 & Medium & High \\
\hline Iowa Coalition & 3 & Medium & Medium \\
\hline Kentucky Coalition* & 3 & High & Medium \\
\hline Minnesota Coalition & 2 & Medium & Low \\
\hline $\begin{array}{l}\text { Mountain States } \\
\text { Pediatric Disaster } \\
\text { Surge Coalition }\end{array}$ & 1 & High & Medium \\
\hline Oregon Coalition & No Data & High & Low \\
\hline $\begin{array}{l}\text { Southeastern } \\
\text { Regional Pediatric } \\
\text { Disaster Surge } \\
\text { Network* }\end{array}$ & 3 & Medium & Medium \\
\hline
\end{tabular}

Table. 1 to be Cont... 


\begin{tabular}{|c|c|c|c|}
\hline \multicolumn{2}{|c|}{3} & Medium & Medium \\
\hline Texas Coalition & 2 & Low \\
\hline $\begin{array}{c}\text { Washington State } \\
\text { Coalition }\end{array}$ & 3 & Medium & High \\
\hline \multicolumn{2}{|c|}{ Intrastate Networks } & Medium \\
\hline $\begin{array}{c}\text { Arizona Healthcare } \\
\text { Coalition } \\
\text { Southeastern }\end{array}$ & 3 & Medium & Low \\
\hline $\begin{array}{c}\text { Colorado Coalition } \\
\begin{array}{c}\text { Coyote Crisis } \\
\text { Collaborative }\end{array}\end{array}$ & 2 & Low & Medium \\
\hline $\begin{array}{c}\text { Ohio Coalition* } \\
\text { San Bernardino (CA) } \\
\text { County Coalition }\end{array}$ & 2 & Medium & Medium \\
\hline $\begin{array}{c}\text { San Francisco } \\
\text { Coalition }\end{array}$ & 2 & Low & Medium \\
\hline $\begin{array}{c}\text { Southern California } \\
\text { Coalition }\end{array}$ & 2 & Medium & \\
\hline
\end{tabular}

*Indicates the network is primarily located in the Appalachian region

Table 1. Network Names, Stage of Network Development, Density, and Intensity of Collaboration

Ten interstate $(59.0 \%$ of identified networks) and seven intrastate networks $(41.0 \%$ of identified networks) were identified via the second survey, with interstate defined as network collaborations that existing in more than one state (i.e. multiple hospitals in multiple states to form one network) and intrastate defined as network collaborations within a single state (i.e. multiple hospitals in one state to form one network). Two Appalachian networks (Kentucky Coalition and the Southeastern Regional Pediatric Disaster Surge Network) were interstate and the other (the Ohio Coalition) was intrastate. Below, Table 2 displays the percentage of selfreported fund-sharing ranging from "not at all" to a "great extent" for each network.

\begin{tabular}{|c|c|c|c|c|c|}
\hline Network Label & Not at All & A Little & Some & A Lot & Great Extent \\
\hline \multicolumn{6}{|c|}{ Interstate Networks } \\
\hline $\begin{array}{l}\text { Florida Children's Preparedness } \\
\text { Coalition }\end{array}$ & $100.0 \%$ & $0.0 \%$ & $0.0 \%$ & $0.0 \%$ & $0.0 \%$ \\
\hline Illinois Coalition & $80.0 \%$ & $20.0 \%$ & $0.0 \%$ & $0.0 \%$ & $0.0 \%$ \\
\hline Iowa Coalition & $40.0 \%$ & $0.0 \%$ & $0.0 \%$ & $0.0 \%$ & $60.0 \%$ \\
\hline Kentucky Coalition* & $25.0 \%$ & $38.0 \%$ & $13.0 \%$ & $13.0 \%$ & $13.0 \%$ \\
\hline Minnesota Coalition & $67.0 \%$ & $0.0 \%$ & $0.0 \%$ & $0.0 \%$ & $33.0 \%$ \\
\hline Mountain States Pediatric Disaster Surge Coalition & $89.0 \%$ & $0.0 \%$ & $0.0 \%$ & $0.0 \%$ & $11.0 \%$ \\
\hline Oregon Coalition & \multicolumn{5}{|c|}{ No Data } \\
\hline $\begin{array}{l}\text { Southeastern Regional Pediatric Disaster Surge } \\
\text { Network* }\end{array}$ & $100.0 \%$ & $0.0 \%$ & $0.0 \%$ & $0.0 \%$ & $0.0 \%$ \\
\hline Texas Coalition & $0.0 \%$ & $0.0 \%$ & $0.0 \%$ & $25.0 \%$ & $75.0 \%$ \\
\hline Washington State Coalition & $0.0 \%$ & $0.0 \%$ & $100.0 \%$ & $0.0 \%$ & $0.0 \%$ \\
\hline \multicolumn{6}{|c|}{ Intrastate Networks } \\
\hline Arizona Healthcare Coalition Southeastern & $100.0 \%$ & $0.0 \%$ & $0.0 \%$ & $0.0 \%$ & $0.0 \%$ \\
\hline Colorado Coalition & $88.0 \%$ & $12.0 \%$ & $0.0 \%$ & $0.0 \%$ & $0.0 \%$ \\
\hline Coyote Crisis Collaborative & $100.0 \%$ & $0.0 \%$ & $0.0 \%$ & $0.0 \%$ & $0.0 \%$ \\
\hline Ohio Coalition* & $100.0 \%$ & $0.0 \%$ & $0.0 \%$ & $0.0 \%$ & $0.0 \%$ \\
\hline San Bernardino (CA) County Coalition & $67.0 \%$ & $0.0 \%$ & $33.0 \%$ & $0.0 \%$ & $0.0 \%$ \\
\hline San Francisco Coalition & $34.0 \%$ & $33.0 \%$ & $33.0 \%$ & $0.0 \%$ & $0.0 \%$ \\
\hline Southern California Coalition & $61.0 \%$ & $13.0 \%$ & $13.0 \%$ & $13.0 \%$ & $1.0 \%$ \\
\hline
\end{tabular}

*Indicates the network is primarily located in the Appalachian region

Table 2. Network Fund Sharing

Three of the 17 networks were located in the Appalachia region - Kentucky Coalition, Southeastern Regional Pediatric Disaster Surge Network, and the Ohio Coalition. Appalachian (2/3) and nonAppalachian networks (8/14) were more likely to be interstate networks than intrastate networks. The Appalachian networks were equally as likely to be high $(1 / 3)$, medium $(1 / 3)$, or low density $(1 / 3)$; nonAppalachian networks were most likely to be medium density $(8 / 14)$ and least likely to be low density (2/14). Appalachian networks were 
more likely to be medium intensity (2/3); non-Appalachian networks were most likely to be medium intensity $(8 / 14) ; 3 / 14$ were high and $3 / 14$ were low intensity. Appalachian networks were most likely to be in stage 3 of network development (2/3); non-Appalachian networks were most likely to be in stage $2(7 / 13)$ and least likely to be in stage 1 (1/13). Only one Appalachian network, the Kentucky Coalition, reported any fund sharing; in contrast, 10/13 non-Appalachian networks reporting at least some fund sharing.

\section{Discussion}

Operating in Appalachia was associated with less fund sharing among networks, although Appalachian networks were more likely to have achieved the highest stage of network development. Overall, increased network intensity (particularly increased levels of fund sharing) among pediatric networks may improve network operations and collaboration and subsequently the health of individuals who live in Appalachian states. The results suggest that the majority of pediatric networks do not engage in any fund sharing at all. This lack of high-level collaboration may lead to increased risk of adverse and poor health outcomes for the vulnerable pediatric population during a hazardous event. Collaborative efforts such as networks are valuable because they provide both surge and non-surge pediatric capacity.

\section{Conclusion}

Pediatric networks in Appalachia can improve coordination among health providers in the Appalachian region via increased evidenced based organizational changes that higher levels of collaboration and creation of strategies centered on preparedness, emergency operations, and medical surge. Because rural hospitals and care providers must often operate with fewer resources, struggle with higher per capita costs, and fewer service providers per capita [3] it is imperative that more networks are created and sustained. The few Appalachian networks identified in our survey are doing important work in an underserved and disadvantaged region. Further studies should evaluate barriers to high density and intensity networks and determine ways to facilitate pediatric healthcare network development in Appalachia.

Conflict of interest: The author has declared no conflict of interest.

\section{References}

1. Bush ML, Alexander D, Noblitt B, Lester C, Shinn JB, et al. (2015) Pediatric hearing healthcare in Kentucky's Appalachian primary care setting. Commu Health 40: 762-768.

2. Remick K, Gausche-Hill M, Joseph MM, Brown K, Snow SK, et al. (2018) Pediatric Readiness in the Emergency Department. Pediatr 142: e20182459.

3. Horney JA, Nguyen M, Cooper J, Simon M, Ricchetti-Masterson K, et al. (2013) Accounting for vulnerable populations in rural hazard mitigation plans: Results of a survey of emergency managers. J Emerg Manag 11: 201-211.

4. Institute of Medicine Committee on the Future of Emergency Care in the US Health System. Report Brief: The Future of Emergency Care in the United States Health Care System. 2006 [Internet]. Washington (DC): Institute of Medicine.

5. American Academy of Pediatrics Committee on Pediatric Emergency Medicine (2004) Overcrowding crisis in our nation's emergency departments: Is our safety net unraveling? Pediatr 114: 878-888.

6. Hostetler MA, Mace S, Brown K, Finkler J, Hernandez D, et al. (2007) Emergency department overcrowding and children. Pediatr Emerg Care 23: 507-515.

7. LeBaron J, Culberson MC, Wiley JF, Smith SR (2010) "Be Quick": A systems response to overcrowding in the pediatric emergency department. Pediatr Emerg Care 26: 808-813.
8. Gausche-Hill M, Schmitz C, Lewis, RJ (2007) Pediatric preparedness of US emergency departments: a 2003 survey. Pediatr 120: 1229-1237.

9. Sills MR, Hall M, Fieldston ES, Hain PD, Simon HK, et al. (2011) Inpatient capacity at children's hospitals during pandemic (H1N1) 2009 outbreak, United States. Emerg Infect Dis 17: 1685-1691.

10. Kanter RK, Moran JR (2007) Hospital emergency surge capacity: an empiric New York statewide study. Ann Emerg Med. 50: 314-319.

11. National Commission on Children and Disasters Report to the President and Congress. AHRQ Publication No. 10-M037. 2010 [Internet]. Rockville (MD): Agency for Healthcare Research.

12. Ginter PM, Wingate MS, Rucks AC, Vasconez RD, McCormick LC, et al. (2006) Creating a regional pediatric medical disaster preparedness network: imperative and issues. Matern Child Health J, 10: 391- 396.

13. Krug SE, Needle S, Schonfeld D, Aird L, Hurley H, et al. (2012) Improving pediatric preparedness performance through strategic partnerships. Disaster Med Pub 6: 94-96.

14. Ginter PM, Rucks AC, Duncan WJ, Wingate MS, Beeman SK, et al. (2010) Southeastern Regional Pediatric Disaster Surge Network: a public health partnership. Pub Health Rep 125: 117-26.

15. Zahner SJ (2005) Local public health system partnerships. Pub Hlth Rep 120: 76-83.

16. PHAB (2013) Public Health Accreditation Board. Public Health Accreditation Board Standards \& Measures.

17. Institute of Medicine (1996) Health communities: New partnerships for the future of public health. Washington, D.C.: National Academies Press.

18. Wisconsin Department of Health and Family Services (2002) Healthiest Wisonsin 2010: A partnership plan to improve the health of the public. Madison: Wisconsin Department of Health and Family Services.

19. Rambhia KJ, Waldhorn RE, Selck F, Mehta AK, Franco C, et al. (2012) A survey of hospitals to determine the prevalence and characteristics of healthcare coalitions for emergency preparedness and response. Biosecur Bioterr 10: 304-313.

20. Toner E, Waldhorn R, Franco C, Courtney B, Norwood A, Rambhia K, et al. (2009) Hospitals rising to the challenge: The first five years of the US Hospital Preparedness Program and priorities going forward. Center for Biosecurity of UPMC for the US Department of Health and Human Services.

21. Gannon-Leary P, Baines S, Wilson R (2006) Collaboration and partnership: A review and reflections on a national project to join up local services in England. J Interprof Care 20: 665-674.

22. Huxham C, Vangen S (2000) Leadership in the shaping and implementation of collaboration agendas: How things happen in a (not quite) joined-up world. Acad Mgmt J 43: 1159-1175.

23. Oliver C (1990) Determinants of inter-organizational relationships: Integration and future directions. Acad Mgt Rev 15: 241-265.

24. Wood DJ, Gary B (1991) Toward a comprehensive theory of collaboration. J Applied Behav Sci 27: 139-162.

25. Alter C, Hage J (1993) Organizations working together. Newbury Park, CA: Sage.

26. Trist E (1983) Referent organizations and the development of inter-organizational domains. Human Relations 36: 269-284.

27. Van De Ven AH, Ferry D (1980) Measuring and Assessing Organizations. New York: Wiley. 
28. Caplow T (1964) Principles of organization. New York: Harcourt Brace.

29. Evan WM (1966) The organization set: toward a theory of interorganizational relations. In J.D. Thompson (ed.). Approaches to organizational design. Pittsburgh, PA: University of Pittsburgh Press.

30. Ring PS, Van de Ven AH (1994) Developmental processes of cooperative interorganizational relationships. Acad Mngt Rev 19: 91-118.

31. Van De Ven AH (1976) On the nature, formation, and maintenance of relationships among organizations. Acad Mgt Rev 1: 24-36.
32. Whetten D (1981) Interorganizational relations: A review of the field. J Higher Educ 52: 1-28.

33. Singer HH, Kegler MC (2004) Assessing interorganizational networks as a dimension of community capacity: Illustrations from a community intervention to prevent lead poisoning. Health Educ Behav 31: 808-821.

34. Isset KR, Provan KG (2005) The evolution of dyadic interorganizational relationships in a network of publicly funded nonprofit agencies. J Pub Ad Res and Theory 15: 149-165. 